\title{
Transurethral Prostate Biopsy
}

National Cancer Institute

\section{Source}

National Cancer Institute. Transurethral Prostate Biopsy. NCI Thesaurus. Code C93198.

Biopsy of the prostate obtained by a needle inserted through the urethral wall. 